\title{
EVALUATION OF IN-VITRO ANTIOXIDANT AND FIBRINOLYTIC ACTIVITY OF FLAVONOID-RICH FRACTION FROM THE WHOLE PLANT OF WEDELIA CHINENSIS
}

\author{
PAVITHRA $\mathbf{S}^{1}$, MANIBALA J ${ }^{1}$, RAMACHANDRAN J ${ }^{2 *}$ \\ ${ }^{1}$ Department of Biotechnology, Prathyusha Engineering College, Chennai, Tamil Nadu, India. ${ }^{2}$ Department of Biochemistry, Gloris Biomed \\ Research Centre (P) Ltd., Chennai, Tamil Nadu, India. Email: bharathirams@gmail.com
}

Received: 11 July 2016, Revised and Accepted: 06 September 2016

\section{ABSTRACT}

Objective: The fundamental objective of this research is to evaluate the antioxidant and fibrinolytic properties of whole plant extracts of Wedelia chinensis.

Methods: The extract was subjected to maceration process in an incubator for $4 \mathrm{hrs}$ at 150 rotations/minute (rpm), $50^{\circ} \mathrm{C}$. The plant material was left to macerate for $20 \mathrm{hrs}$. The in-vitro antioxidant property of the methanolic extract was determined using thin-layer chromatography (TLC) autobiography, 2, 2- Azino-bis-3 ethyl benzthiazoline-6 sulfonic acid (ABTS), radical scavenging assay, metal chelating, nitric oxide, and superoxide. In-vitro thrombolytic model was performed on flavonoid fraction of W. chinensis.

Results: Maximum inhibition was observed in the flavonoid fraction concentration of $20 \mu \mathrm{g} / \mathrm{mL} W$. chinensis as $75.64 \%$ in ABTS radical scavenging activity, $78.0 \%$ in metal chelation, $84.34 \%$ innitric oxide radical scavenging activity, and $81.8 \%$ in super oxide radical scavenging assay. Clot lysis activity of $W$. chinensis was $20.43 \pm 0.34,35.3 \pm 1.10,43.76 \pm 0.67$, and $63.42 \pm 1.65$ respectively. Hemolysis rates were $<5 \%$.

Conclusion: On exhaustive survey on $W$. chinensis, it was found that this herb has been used for various activities that potentiated the folklore use for treating mankind. Medicines derived from plant origin will have a long history of use for the prevention and treatment of various diseases. In our study, it was found that the flavonoid fraction of W. chinensis possess antioxidant and thrombolytic properties. However, in vivo clot dissolving properties and active component(s) responsible for $W$. chinensis are yet to be discovered which can be used to treat cardiovascular diseases.

Keywords: Antioxidant, Cardiovascular diseases, Fibrinolysis, Hemolytic, Radical scavenging assay, Wedelia chinensis.

(C) 2016 The Authors. Published by Innovare Academic Sciences Pvt Ltd. This is an open access article under the CC BY license (http://creativecommons. org/licenses/by/4. 0/) DOI: http://dx.doi.org/10.22159/ajpcr.2016.v9s3.13419

\section{INTRODUCTION}

Reactive oxygen species play an important role in degenerative or pathological processes, such as aging [1], cancer, coronary heart disease, Alzheimer's disease [2], neurodegenerative disorders, atherosclerosis, diabetes, and inflammation [3]. Several anti-inflammatory, digestive, anti-necrotic, neuroprotective, and hepatoprotective drugs have recently been shown to have antioxidant and/or radical scavenging mechanisms as well [4]. In the present scenario, usage of the traditional medicinal system is chosen as primary health care. There is a need for alternative medicinal source, and thus a drug from natural plants satisfies this need as they have innumerable benefits. There is a great deal of research work going on to formulate drugs by classifying the antioxidant and antibacterial activity of the plants. World Health Organization has recommended the evolution of the effectiveness of plants in a condition where there is lack of safe synthetic drugs. Plants are rich in phenolic compounds and flavonoids which have been reported to exert multiple biological effects, such as antioxidant activities, free radical scavenging abilities, anti-inflammatory, and anti-carcinogenic [5]. The antioxidant activity of phenols is mainly due to their redox properties, which allow them to act as reducing agents, electron/hydrogen donators, and singlet oxygen quenchers. In addition, they have a metal chelating potential [6] Crude extracts of herbs and other plant materials are rich in phenols and flavonoids, and several studies reported a positive linear correlation between the total phenolic compounds and the antioxidant activities of Methanolic extracts of different plant species [7]. Wedelia chinensis belonging to family Asteraceae has great importance in Ayurvedic, Sidha, and Unani systems of traditional medicine [8]. W. chinensis is a common ingredient of anti-inflammatory herbal medicines. They are considered as tonic, alternative, and used in the treatment of coughs, cephalalgia, skin diseases, and alopecia. The juice of the leaves is much used as a snuff in cephalalgia. The seeds and flowers, as well as the leaves, are used in decoction, in the quantity of half of teacupful twice daily, as anaperients [9]. W. chinensis plant is very specific for 'viral hepatitis' [10]. Traditionally, the fruits, leaves, and stem are used in childbirth and in the treatment of bites and stings, fever, and infection. The decoction of the plant is used in uterine hemorrhage and menorrhagia.

Thrombosis is one of the leading causes of thromboembolic disorders affecting million persons worldwide. Several plants used for the treatment of thromboembolic diseases in different systems of traditional medicine have shown anticoagulant/antithrombotic activity, and such plants claimed in the traditional system still remain to be scientifically investigated [11]. A blood clot (thrombus) developed in the circulatory system due to the failure of homeostasis causes vascular blockage and while recovering leads to serious consequences in atherothrombotic diseases, such as acute myocardial or cerebral infarction, at times leading to death. Commonly used thrombolytic agents are alteplase, anistreplase, streptokinase, urokinase, and tissue plasminogen activator to dissolve clots [12]. All available thrombolytic agents still have significant shortcomings, including the need for large doses to be maximally effective, limited fibrin specificity, and bleeding tendency. Because of the shortcomings of the available thrombolytic drugs, attempts are underway to develop improved recombinant variants of these drugs [13].

The traditional herbal medicines increased an uprising interest since couple of decades due to their incredible pharmacological activities, economic viability, and less side effects in different health-care management system [14]. Thus, tremendous efforts have also been directed toward the discovery and development of natural products with anti-platelet [15], anti-coagulant, antithrombotic and thrombolytic activity of the plants that are not documented. Epidemiologic studies 
have provided evidence that foods with experimentally proved antithrombotic effect could reduce the risk of thrombosis. The survey on review of literature revealed the availability of seldom information on protease activity from plant lattices. They are Papain (Carica papaya), Euphorbain (Euphorbia lathyris), Curcain Uatropa curcas), Calatropin (Calatropis gigantean), and Eravatamin (Ervatomia coronaria). Fibrinolytic properties can be found in a variety of medicine plants and they could effectively prevent cardiovascular diseases. Ageratum conyzoides, Leea indica, Leucas aspera, Senna sophera, and Solanum torvum plant parts showing thrombolytic activity have also been reported. They are used as traditional medicines for cardiac diseases and blood purification. Recently, A. conyzoides was reported to have hematological and lymphocyte increasing activity. Roots, leaves, and seeds of $C$. suffruticosa are used in the treatment of bleeding and cerebrospinal meningitis. $W$. chinensis is one among these traditional plants as mentioned above which possess greater antioxidant and fibrinolytic properties. The major aim of our study is to analyze the antioxidant and fibrinolytic effect of $W$. chinensis thus by ratifying the fact that they have the potential to play a vital role in reducing the risk of developing cardiovascular diseases and many more.

\section{METHODS}

Collection of plants

W. chinensis were collected from herbal garden of Sri Sairam Sidha Medical College and Research Centre, West Tambaram, Chennai-44, Tamil Nadu, India.

\section{Collection of human blood}

The volume of $5 \mathrm{ml}$ human blood was collected from interested volunteer to donate blood for the experiment.

\section{Preliminary phytochemical analysis of $W$. chinensis}

Shade-dried plants (200 g) were pulverized separately and subjected to extraction by continuous hot extraction (soxhlet) method. The extraction was done with methanol solvent. Every time, the residue was dried in air at room temperature and later used for extraction. The extracts were evaporated using a rotary evaporator and the percentage yield was thus recorded. Dried extracts were stored at $4^{\circ} \mathrm{C}$ in airtight containers for further studies. Concentrated extracts were subjected to various chemical tests to detect the presence of different phytoconstituents [16].

\section{Extraction of flavonoids}

Extraction method used in this study was a modification of the method exercised by [17]. Dried and powdered plant material (10 g) was successively extracted in a flask using $50 \%$ methanol. The extract was subjected to maceration process in an incubator for 4 hrs at 150 rotations/minute, $50^{\circ} \mathrm{C}$. The plant material was left to macerate for $20 \mathrm{hrs}$. Following this procedure, the extract was filtered using a blue band filter paper and Buchner funnel. The hydro alcohol solution was evaporated to dryness under a reduced pressure. Hydrolic extract was treated with petroleum ether $\left(40^{\circ}-60^{\circ}\right)$ in a separation funnel and transferred in the aqueous phase to another separation funnel. After ethyl acetate was added, the funnel was gently mixed. It was found that ethyl acetate was a part of the separation funnel. The ethyl acetate was evaporated to dryness under a reduced pressure. This extract was used for chromatographic analysis. Three thousand micrograms of this extract were dissolved in $1 \mathrm{ml}$ methanol. Some of these samples were diluted and made available for TLC chromatographic analysis.

\section{Analysis of flavonoids using TLC}

The flavonoid fraction (5 mg) was dissolved in $10 \mathrm{ml}$ methanol. TLC was performed using silica plate according to Wagner and Bladt [18]. These plates were actually aluminum sheets coated with silica gel GF254 (Merck 20×20 cm). Flavonoids were analyzed on TLC plates. Concentrated ethyl acetate solution was directly filled with standard flavonoid solutions $1 \mathrm{~cm}$ from the bottom (as spots) using a capillary tube on the silica plates and using ethyl acetate: Acetic acid: Formic acid: Water (100:11:11:27 v/v) as a running (mobile phase) solvent. After that, at least half an hour of solvent vaporization inside the running tank was expected to achieve balance. Then, a plate was developed in a balanced running tank. The running process was allowed to leave the mobile phase to reach the top point of up to $1.5 \mathrm{~cm}$. The developed plates were removed from the tank and then dried in a fume cupboard. Colored and colorless bands emerged on the plate under the UV light at 254 and $360 \mathrm{~nm}$.

\section{In-vitro antioxidant activity}

\section{2, 2'-azino-bis-3 ethyl benzthiazoline-6 sulfonic acid (ABTS) radical scavenging assay}

ABTS radical scavenging activity of flavonoid fraction was determined according to Re et al. [19] ABTS radical was freshly prepared by adding $5 \mathrm{ml}$ of $4.9 \mathrm{mM}$ ABTS solution and kept for 16 hrs in dark. This solution was diluted with distilled water to yield an absorbance of 0.70 at $734 \mathrm{~nm}$ and the same was used for antioxidant assay. The final reaction mixture of standard group was made up to $1 \mathrm{ml}$ with $950 \mu \mathrm{L}$ of ABTS solution and $50 \mu \mathrm{L}$ of vitamin C. Similarly, in the test group, $1 \mathrm{ml}$ reaction mixture comprised $950 \mu \mathrm{L}$ of ABTS solution and $50 \mu \mathrm{L}$ of extract solution. The reaction mixture was vortexed for 10 seconds and after 6 minutes absorbance was recorded at $734 \mathrm{~nm}$ against distilled water using ELICO (SL 150) UV-visible spectrophotometer and compared with the control ABTS solution. Ascorbic acid was used as reference anti-oxidant compound.

\section{Metal chelating activity}

Metal chelating capacity of flavonoid fraction was measured according to the method described by Gülçin et al., [20]. $1 \mathrm{ml}$ of different concentrations of methanolic extract was added to a $0.05 \mathrm{ml} 2 \mathrm{mM}$ Ferric chloride solution. The reaction was initiated by the addition of $0.2 \mathrm{~mL}$ of $5 \mathrm{mM}$ ferrozine, and the mixture was shaken vigorously. After 10 minutes, the absorbance of the solution was measured at $562 \mathrm{~nm}$ against blank. All reading was taken in triplicate and Ascorbic acid was used as the standard. The percentage inhibition of ferrozine- Fe2+ complex was calculated by the following equation.

$\%$ inhibition of ferrozine $\mathrm{Fe} 2+$ complex $=\frac{\left(\mathrm{A}_{0}-\mathrm{A}_{1}\right)}{\mathrm{A}_{0}} \times 100$

Where, $A_{0}$ : Absorbance of control, $A_{1}$ : Absorbance of different solvent extract.

\section{Nitric oxide radical scavenging activity}

Nitric oxide radical scavenging capacity of flavonoid fraction was measured according to the method described by Olabinri et al., [21]. $0.1 \mathrm{ml}$ of $10 \mathrm{mM}$ sodium nitroprusside in phosphate buffer $(0.2 \mathrm{M}$, pH-7.8) was mixed with different concentrations of flavonoid fraction and incubated at room temperature for 150 minutes. After incubation period, $0.2 \mathrm{ml}$ of Griess reagent (1\% sulfanilamide, $2 \%$ phosphoric acid, and $0.1 \% \mathrm{~N}$-(1-naphthyl ethylenediamine dihydrochloride) were added. The absorbance of the reaction mixture was read at $546 \mathrm{~nm}$ against blank. All readings were taken in triplicate, and ascorbic acid was used as the standard. The \% inhibition was calculated by the following equation.

$\%$ inhibition of ferrozine Fe $2+$ complex $=\frac{\left(\mathrm{A}_{0}-\mathrm{A}_{1}\right)}{\mathrm{A}_{0}} \times 100$

Where, $A_{0}$ : Absorbance of control, $A_{1}$ : Absorbance of different solvent extract.

\section{Superoxide radical scavenging assay}

The assay for superoxide anion radical scavenging activity was supported by Riboflavin-light- Nitro blue tetrazolium chloride (NBT) system [22]. Briefly, $1 \mathrm{~mL}$ of sample was taken at different concentrations ( 5 to $20 \mu \mathrm{g} / \mathrm{mL}$ ) and mixed with $0.5 \mathrm{ml}$ of phosphate 
buffer ( $50 \mathrm{mM}, \mathrm{pH} 7.6), 0.3 \mathrm{ml}$ riboflavin $(50 \mathrm{mM}), 0.25 \mathrm{~mL}$ phenyl methanesulfonate $(2 \mathrm{mM})$, and $0.1 \mathrm{ml} \mathrm{NBT}(0.5 \mathrm{mM})$. The reaction was started by illuminating the reaction mixture using a fluorescent lamp. After 20 minutes of incubation, the absorbance was measured at $560 \mathrm{~nm}$. Ascorbic acid was used as standard. The scavenging ability of the plant extract was determined by the following equation.

Scavenging effect $(\%)=\frac{1 \text {-Absorbance of sample }}{\text { Absorbance of control }} \times 100$

\section{Detection of antioxidant agents by TLC bioautography}

An aliquot of flavonoid fraction $(1 \mathrm{mg} / \mathrm{ml}, 3 \mathrm{ml})$ or individual pure isolate methanol solutions $(1.0 \mathrm{mg} / \mathrm{ml}, 2 \mathrm{ml})$ was directly deposited (as spots or bands) onto the TLC plates. TLC plates were developed in a pre-saturated solvent chamber with ethyl acetate: Acetic acid: Formic acid: Water (100:11:11:27) as developing reagents until the solvent front reached $1 \mathrm{~cm}$ from the top of plates. The developed TLC plates were then removed from the chamber, and allowed to air-dry for 30 minutes, followed by spraying with a $2.54 \mathrm{mM}$ ABTS methanol solution for derivatization. By derivatization, substances that do not respond to visible or UV light can become detectable. Bands with the ABTS scavenging activity were observed as white yellow bands on a green background.

\section{Fibrinolysis assay of $W$. chinensis flavonoid fraction}

Various volumes $(10,20,30,40,50 \mu \mathrm{L})$ of the flavonoid fraction were added to $2 \mathrm{ml}$ of plasma as positive controls and maintained at $4^{\circ} \mathrm{C}$ for $24 \mathrm{hrs}$. A mixture containing $2 \mathrm{ml}$ plasma and particular volume of ethyl alcohol was utilized as a negative control. After inserting labeled clots to $50 \mu \mathrm{L}$ plasma, samples were taken at 7 consecutive hours (between half an hour and every $1 \mathrm{hr}$ ) and enhanced to $2 \mathrm{ml}$ by $0.1 \mathrm{M}$ Phosphatebuffered saline. The fluorescence intensity of the samples was measured in excitation of $495 \mathrm{~nm}$.

\section{Fibrin clot lysis effect of $W$. chinensis flavonoid fraction on human fibrin}

Experiments for clot lysis were carried as reported earlier Prasad et al., [23]. Briefly, $4 \mathrm{ml}$ venous blood drawn from the healthy volunteers was distributed in 8 different pre-weighed sterile microcentrifuge tube $(0.5 \mathrm{ml} /$ tube $)$ and incubated at $37^{\circ} \mathrm{C}$ for 45 minutes. After clot formation serum was completely removed without disturbing the clot and each tube having clot was again weighed to determine the clot weight (clot weight = weight of clot containing tube - weight of tube alone). To each micro centrifuge tube containing pre-weighed clot, $100 \mu \mathrm{L}$ of methanolic extracts of the $W$. chinensis flavonoid extract were added separately. As a positive control, $100 \mu \mathrm{L}$ of streptokinase and as a negative nonthrombolytic control, $100 \mu \mathrm{L}$ of distilled water were separately added to the control tubes numbered. All the tubes were then incubated at $37^{\circ} \mathrm{C}$ for 90 minutes and observed for clot lysis. After incubation, fluid released was removed and tubes were again weighed to observe the difference in weight after clot disruption. Difference obtained in weight taken before and after clot lysis was expressed as percentage of clot lysis.

\section{RESULTS}

Phytochemical analysis of the $W$. chinensis methanol extract Phytochemical screening provides basic information about medicinal importance of a plant extract. In this study, evaluation of qualitative analysis of the chemical constituents of $W$. chinensis showed the presence of various secondary metabolites, alkaloid, flavonoids, tannins, polyphenols, and terpenes. Phytochemical screening indicated the presence of flavonoids and tannin, which are phenolic compounds. Plant phenolics are known to be anti-oxidants and free radical scavengers.

Thin-layer chromatography analysis for the partial characterization of flavonoid fraction of $W$. chinensis

The partial characterization of the flavonoid fraction of $W$. chinensis was carried out on pre-coated silica gel plates $\left(60 \mathrm{~F}_{254}\right.$ Merck, USA)
The efficient solvent system used for the flavonoid extract was ethyl acetate: Acetic acid: Formic acid: Water (100:11:11:27 v/v). Finally, chromatogram plates developed were viewed under 240 and $360 \mathrm{~nm}$ (Fig. 1). TLC is a standard technique, which separates low and high molecular weight organic compounds according to their polarity.

In vitro antioxidant properties of $\mathrm{W}$. chinensis flavonoid fraction

\section{ABTS radical scavenging assay}

Flavonoid fraction of $W$. chinensis exhibited a powerful scavenging activity of ABTS radical cations in a concentration-dependent manner (Fig. 2), showing a direct role in catching free radicals. Maximum inhibition was observed in the flavonoid fraction concentration of $20 \mu \mathrm{g} / \mathrm{mL}$ of the extract $(75.64 \%)$ and ascorbic acid $(74.92 \%)$. Minimum inhibition was observed in $5 \mu \mathrm{g} / \mathrm{mL}$ of the extract $(19.23 \%)$ and the ascorbic acid (17.80\%). Free radical (ABTS) scavenging activity of $W$. chinensis extracts might be due to the presence of high-molecular weight phenolics such as catechin and rutin derivatives.

\section{Metal chelating activity}

The metal chelating properties of flavonoids plays an important role in metal-overload diseases and in all oxidative stress conditions involving a transition metal ion. The ability of flavonoids to reduce iron and copper ions and their activity-structure relationships was also investigated. The absorbance of $\mathrm{Fe}^{2+} \mathrm{Ferrozine}$ complex decreased dose dependently. The maximum metal chelating activity was found at $20 \mu \mathrm{g} / \mathrm{ml}$ of flavonoid fraction of W. chinensis (Fig. 3). The result proved that the flavonoid-rich fraction possessed $\mathrm{Fe}^{2+}$ chelating activity and may play a protective role against oxidative damage induced by metal catalyzed decomposition reactions.

\section{Nitric oxide radical scavenging activity}

Nitric oxide injury takes place in most part of the plants through the Peroxynitrite route. Peroxynitrite can directly oxidize low-density

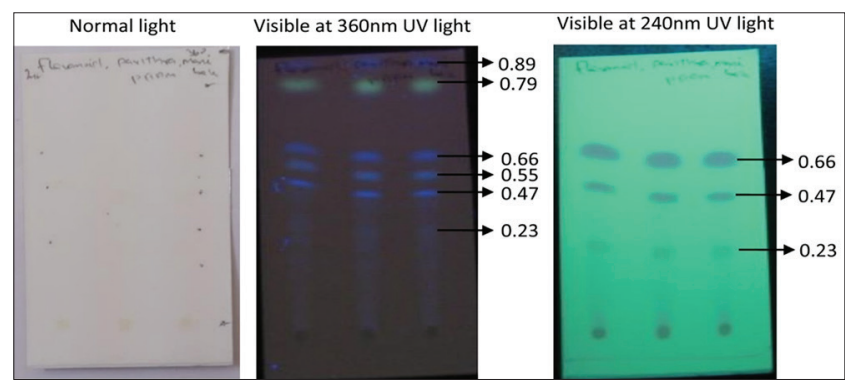

Fig. 1: Thin layer chromatography profile of Wedelia chinensis flavonoid fraction

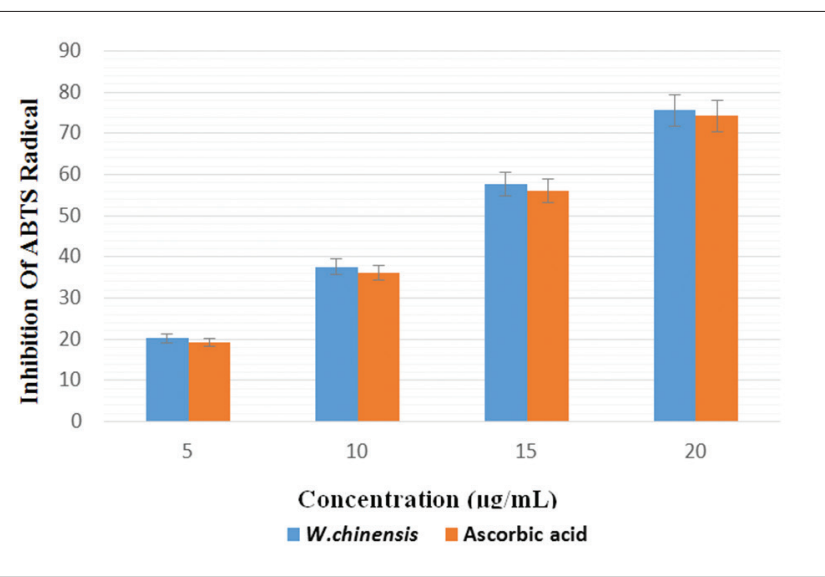

Fig. 2: 2, 2'- azino-bis-3 ethyl benzthiazoline-6 sulphonic acid radical scavenging assay 
lipoproteins resulting in irreversible damage to the cell membrane. Inhibition increased with increasing concentration of the extract. The present study involves four different concentrations of $W$. chinensis flavonoid fraction. Maximum inhibition and minimum inhibition was noted in $20 \mu \mathrm{g} / \mathrm{mL}$ (84.3\%) and $5 \mu \mathrm{g} / \mathrm{mL}$ (28.7\%) of the extract (Fig. 4).

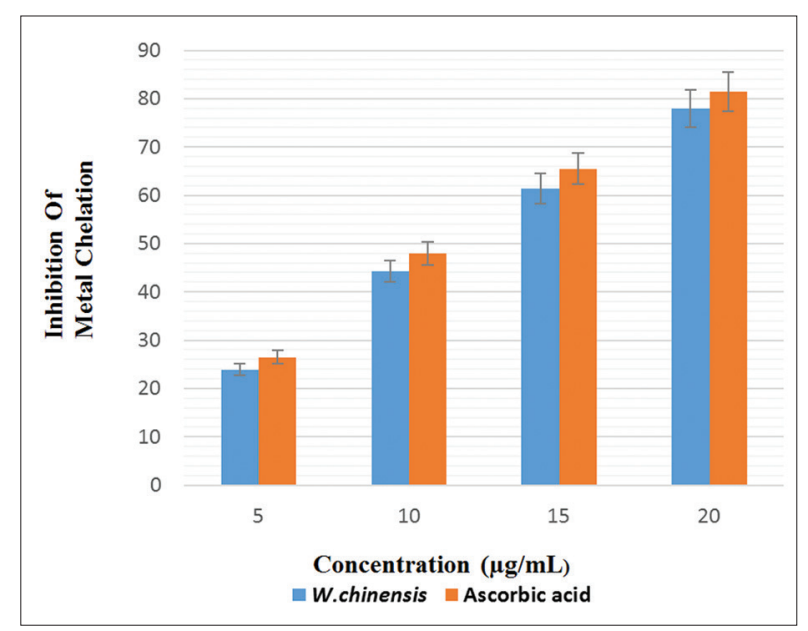

Fig. 3: Metal chelating activity

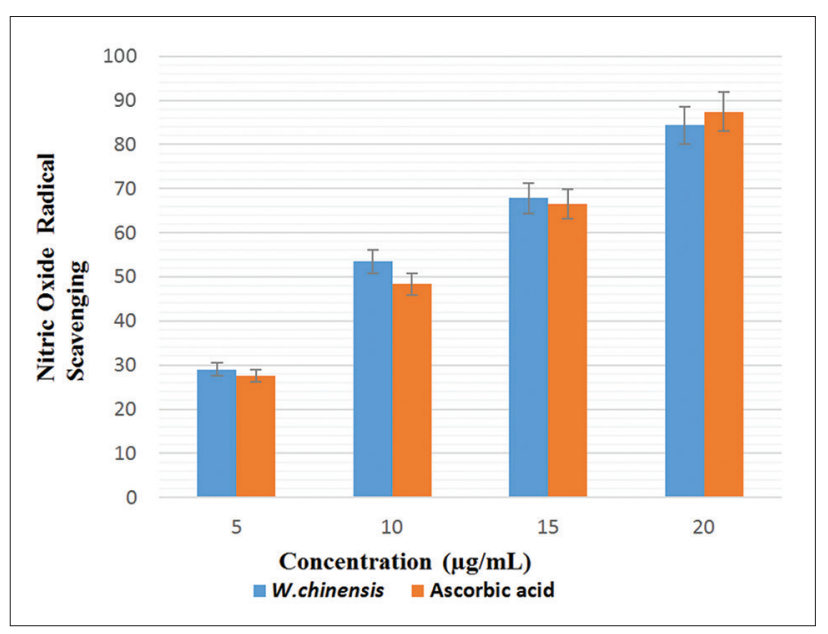

Fig. 4: Nitric oxide radical scavenging activity

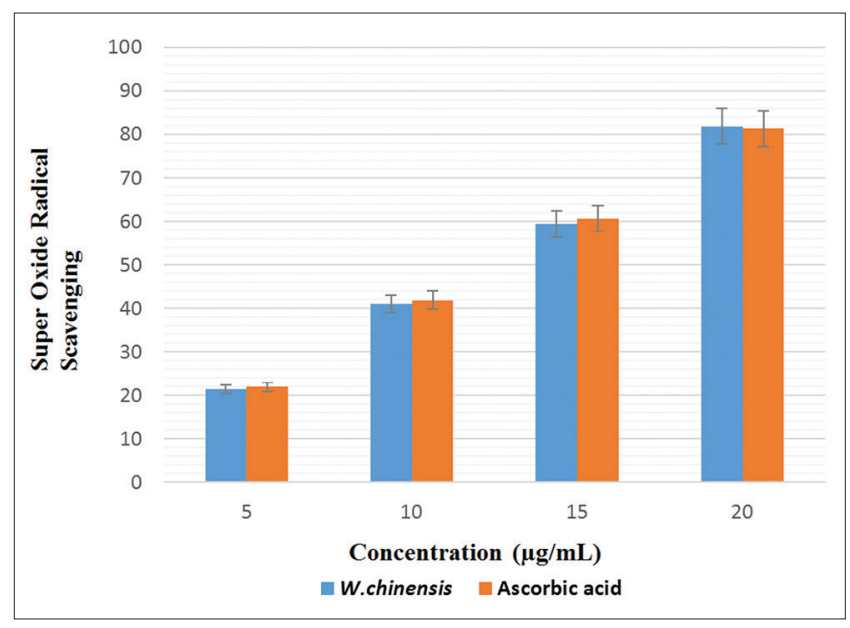

Fig. 5: Superoxide radical scavenging assay

\section{Superoxide radical scavenging assay}

Superoxide radicals by photochemical process decreases NBT in the occurrence of a Riboflavin-light-NBT system, which is one of the standard methods. The total fractions of W. chinensis exhibited potential scavenging activity for superoxide radicals in a concentration dependent manner (Fig. 5).

Detection of antioxidant molecules of $W$. chinensis flavonoid fraction by TLC bio-autography

In this method, the ABTS scavenging activity was observed visually as white yellow spots on a green background. Fig. 6 shows a profile of the antioxidant components in the flavonoid fraction of $W$. chinensis under visible light. The chromatograms observed to have ABTS scavenging activities.

\section{Fibrin clot lysis effect of $W$. chinensis flavonoid fraction on human blood}

The clots along with 90 minutes of incubation at $37^{\circ} \mathrm{C}$, showed $79.13 \%$ clot lysis. However, distilled water (negative control) treated-clots showed only negligible clot lysis (3.17\%). The mean difference in clot lysis percentage between positive and negative control was very significant. Treatment of clots with $W$. chinensis flavonoid fraction provided the clot lysis $19.43,33.3,41.76$ and $61.42 \%$, respectively (Figs. 7 and 8).

\section{Hemolysis test of human blood erythrocytes of $W$. chinensis flavonoid fraction}

Different concentration of $W$. chinensis flavonoid fraction was added to erythrocytes and then hemolysis rate was tested. The results indicated that there were no obvious hemolysis and agglutination effects on human erythrocytes (Fig. 9). Hemolysis rates of high concentration Fibrinolytic enzyme $(15 \mu \mathrm{L}$ and $20 \mu \mathrm{L})$ were a little more than $3 \%$, but low concentration fibrinolytic enzyme $(5 \mu \mathrm{L}$ and $10 \mu \mathrm{l})$ did not hemolyze erythrocytes. On comparison, the hemolysis rate of flavonoid fraction of W. chinensis was $<5 \%$ (Fig. 10).

\section{DISCUSSION}

Although synthetic antioxidants are useful for mankind, it has many toxicological side effects including carcinogenicity. Due to this reason, there has been a particular interest in the potential health benefits of natural anti-oxidants with the strong capacity to scavenge reactive oxygen species. The standard method which is used to detect the presence of phytochemical constituents of methanol extract showed the presence of tannins, terpenoid, flavonoids, steroids, and reducing sugars. Flavonoids, phenolic acids, and tannins present in the plant have grabbed much attention due to their anti-oxidant and free radical scavenging activities which are beneficial for mankind. Suresh et al., [9] had described the phytochemical constituents of ethanol extract of $W$. chinensis was performed by standard methods and the results indicated the presence of tannins, terpenoids, flavonoids, and reducing sugars relatively similar to that of the methanolic extract of $W$. chinensis. Affirming this theory, the study was done on Antioxidant activity by applying an improved ABTS radical cation decolorization assay. In this method, decolorization assay is applied on both lipophilic and hydrophilic antioxidants including flavonoids, hydroxyl cinnamates, carotenoids, and plasma antioxidants. The antioxidant activity is determined by the concentration of antioxidant and duration of reaction on the inhibition of the radical cation. In ABTS, radical scavenging methods inhibitory concentration $50\left(\mathrm{IC}_{50}\right)$ of $80 \mu \mathrm{g} / \mathrm{mL}$, the reference standard Ascorbic acid showed $50 \%$ inhibition at $30 \mu \mathrm{g} / \mathrm{mL}$ on linear correlation between the amount of total phenols and antioxidant capacity [DPPH, ABTS] was similar for the methanolic extract of $W$. trilobata flower [24]. The result proved that the flavonoid-rich fraction possessed $\mathrm{Fe} 2+$ chelating activity and may play a protective role against oxidative damage induced by metal catalyzed decomposition reactions extract could reach $84.08 \%$ and $79.24 \%$, respectively, than other organic solvent extract. 


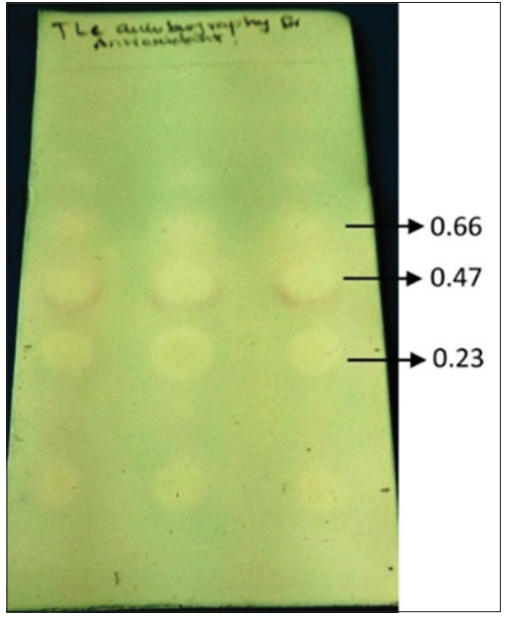

Fig. 6: Detection of antioxidant molecules of Wedelia chinensis

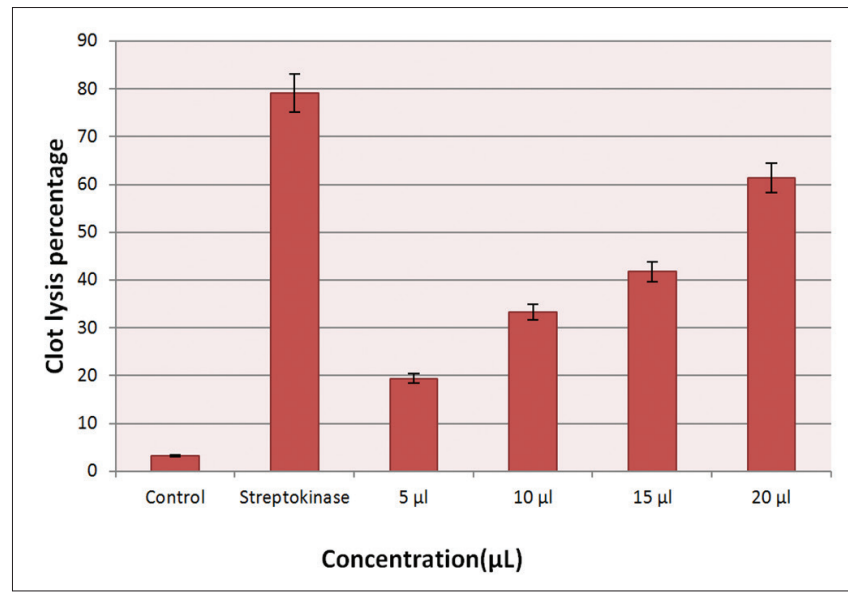

Fig. 7: Fibrin clot lysis percentage of Wedelia chinensis flavonoid fraction in human blood

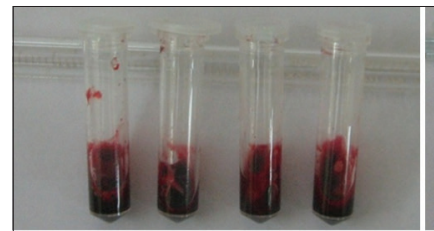

Before Clot Lysis

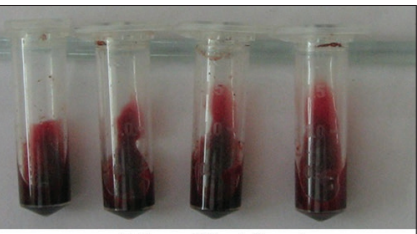

After Clot Lysis
Fig. 8: Fibrin clot lysis effect of Wedelia chinensis flavonoid fraction in human blood

Therefore, the flavonoid extract of $W$. chinensis showed $\mathrm{IC}_{50}$ of $22.34 \mu \mathrm{g} / \mathrm{mL}$ in ABTS radical scavenging activity, $\mathrm{IC}_{50}$ of $89.68 \mu \mathrm{g} / \mathrm{mL}$ in metal chelating activity, $\mathrm{IC}_{50}$ of $66.05 \mu \mathrm{g} / \mathrm{mL}$ in Nitric oxide radical scavenging activity, and $\mathrm{IC}_{50}$ of $80.35 \mu \mathrm{g} / \mathrm{mL}$ in Superoxide radical scavenging. This active antioxidant compound was then monitored by a TLC bioautography method to guide the separation because this method gives a quick access for detection and localization of the active compounds in a complicated plant extract.

Plants may serve as the alternative sources for the development of new anticoagulant agents due to their biological activities. There are compelling scientific evidences demonstrating that the consumption of dietary anticoagulants or phytochemical with anticoagulant properties can ultimately reduce or eliminate the risks of thromboembolic diseases [25-27]. The flavonoid extract of $W$. chinensis possessed a

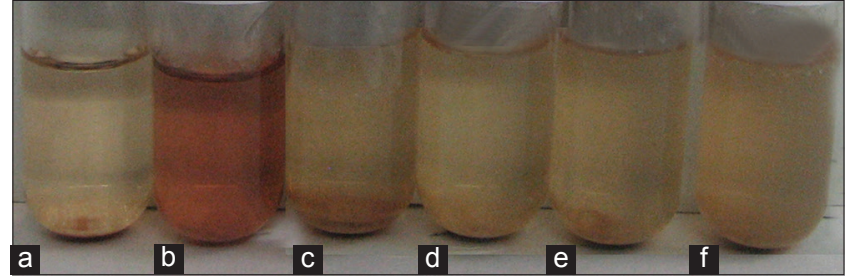

Fig. 9: Hemolysis test of human blood erythrocytes of Wedelia chinensis flavonoid fraction. (a) Normal saline; (b) Distilled water; (c) $5 \mu \mathrm{L}$; (d) $10 \mu \mathrm{L}$; (e) $15 \mu \mathrm{L}$; (f) $20 \mu \mathrm{L}$

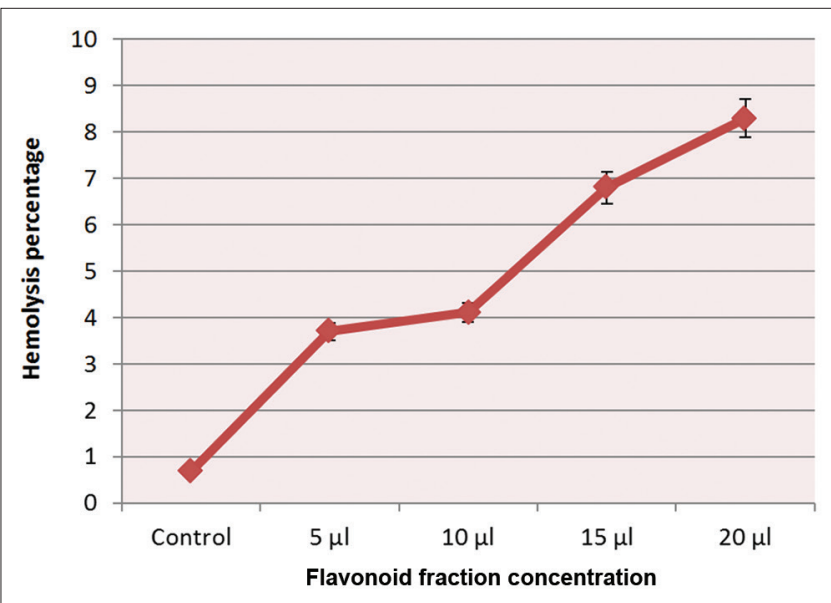

Fig. 10: Hemolysis percentage of Wedelia chinensis flavonoid fraction on human blood erythrocytes.

significant anticoagulant activity, thus showing the potential of plant resources as bioactive materials for therapeutic purposes and for an alternative source to the synthetic anticoagulants. This research focus on natural plants used as antithrombotic or anticoagulant as mentioned in folk medicine.

\section{CONCLUSION}

Natural products from folk remedies have contributed significantly in the discovery of modern drugs and can be an alternative source for the discovery of novel structures with better safety and efficacy. In recent studies, $W$. chinensis has been used to treat prostate cancer which induces selective apoptosis in prostate cancer cells. There is a need for alternative medicinal source in present scenario, and so $W$. chinensis will be a better source to satisfy the need. Approximately $30 \%$ of the pharmaceuticals formulations are prepared from plants across the worldand are considered to be less toxic and free from side effects than the synthetic one. In our study, it was found that flavonoid fraction from $W$. chinensis to possess thrombolytic properties, However, in vivo clot dissolving properties and active component(s) responsible for $W$. chinensis are yet to be discovered. By the above-obtained results, it can be suggested that the application of the $W$. chinensis component maybe accessible for greater section of the society for the treatment ofcardiovascular diseases. Further research, on cell viability tests and in vivo studies, will have important implications in the treatment of cardiovascular diseases which is increasing at an alarming rate.

\section{ACKNOWLEDGMENT}

We record our deep sense of indebtedness and gratitude to the Managing Director of Gloris BioMed Research centre (P) Ltd., Chennai-600078 for their encouragement, technical assistance and support throughout our study. 


\section{REFERENCES}

1. Burns J, Gardner PT, Matthews D, Duthie GG, Lean ME, Crozier A Extraction of phenolics and changes in antioxidant activity of red wines during vinification. J Agric Food Chem 2001;49(12):5797-808.

2. Diaz MN, Frei B, Vita JA, Keaney JF Jr. Antioxidants and atherosclerotic heart disease. N Engl J Med 1997;337(6):408-16.

3. Chen FA, Wu AB, Shieh P, Kuo DH, Hsieh CY. Evaluation of the antioxidant activity of Ruellia tuberosa. Food Chem 2006;94(1):14-8.

4. Lin CC, Huang PC. Antioxidant and hepatoprotective effects of Acathopanax senticosus. Phytother Res 2000;14(7):489-94.

5. Bilto YY, Suboh S, Aburjai T, Abdalla SH. Structure-activity relationships regarding the antioxidant effects of the flavonoids on human erythrocytes. Natl Sci 2012;4(9):740-7.

6. Hazra B, Sarkar R, Biswas S, Mandal N. The antioxidant, iron chelating and DNA protective properties of $70 \%$ methanolic extract of 'Katha' (heartwood extract of Acacia catechu). J Complement Integr Med 2010;7(1):1-20.

7. Alali FQ, Tawaha K, El-Elimat T, Syouf M, El-Fayad M, Abulaila K, et al. Antioxidant activity and total phenolic content of aqueous and methanolic extracts of Jordanian plants: An ICBG project. Nat Prod Res 2007;21(12):1121-31.

8. Koul S, Pandurangan A, Khosa RL. Wedelia chinenis (Asteraceae) - An overview. Asian Pac J Trop Biomed 2012;2:S1169-75.

9. Suresh V, Kumar RM, Suresh A, Kumar NS, Arunachalam G, Umasankar K. CNS activity of ethanol extract of Wedelia chinensis in experimental animals. Int J Pharm Sci Nanotechnol 2010;3(1):881-6.

10. Anonymous. Indian Medicinal Plants-A Compendium of 500 Species. Arya Vaidya Sala, Kottakal: Orient Langman Limited; 1983. p. 404-5.

11. Kumar S, Joseph L, George M, Sharma A. A review on anticoagulant/ antithrombotic activity of natural llants used in traditional medicine. Int J Pharm Sci Rev Res 2011;8(1):70-4.

12. Collen D. Coronary thrombolysis: Streptokinase or recombinant tissuetype plasminogen activator? Ann Intern Med 1990;112(7):529-38.

13. Marder VJ. Recombinant streptokinase: Opportunity for an improved agent. Blood Coagul Fibrinolysis 1993;4(6):1039-40.

14. Chew AL, Jessica JJ, Sasidharan S. Antioxidant and antibacterial activity of different parts of Leucas aspera. Asian Pac J Trop Biomed 2012;2(3):176-80
15. Briggs WH, Folts JD, Osman HE, Goldman IL. Administration of raw onion inhibits platelet-mediated thrombosis in dogs. J Nutr 2001;131(10):2619-22.

16. Harbone JB. Phytochemical Methods: A Guide to Modern Techniques of Plant Analysis. London: Chapman and Hall; 1973. p. 279-80.

17. Zhao M, Ito $\mathrm{Y}$, Tu P. Isolation of a novel flavanone 6-glucoside from the flowers of Carthamus tinctorium (Honghua) by high-speed countercurrent chromatography. J Chromatogr A 2005;1090(1-2):193-6.

18. Wagner H, Bladt S. Plant Drug Analysis. Berlin: Springer-Verlag; 1996.

19. Re R, Pellegrini N, Proteggente A, Pannala A, Yang M, Rice-Evans C. Antioxidant activity applying an improved ABTS radical cation decolorization4200 assay. Free Radic Biol Med 1999;26(9-10):1231-7.

20. Gülçin I, Büyükokuroglu ME, Oktay M, Küfrevioglu OI. Antioxidant and analgesic activities of turpentine of Pinus nigra Arn. Subsp. Pallsiana (Lamb.) Holmboe. J Ethnopharmacol 2003;86(1):51-8.

21. Olabinri BM, Odedire OO, Olaleye MT, Adekunle AS, Ehigie LO, Olabinri PF. In vitro evaluation of hydroxyl and nitric oxide radica scavenging activities of artemether. Res J Biol Sci 2010;5(1):102-5.

22. Beauchamp C, Fridovich I. Superoxide dismutase: Improved assays and an assay applicable to acrylamide gels. Anal Biochem 1971;44(1):276-87.

23. Prasad S, Kashyap RS, Deopujari JY, Purohit HJ, Taori GM, Daginawala HF. Development of an in vitro model to study clot lysis activity of thrombolytic drugs. Thromb J 2006;4:14

24. Chethan J, Sampath Kumara KK, Niranjana SR, Prakash HS. Evaluation of antioxidant and antibacterial activities of methanolic flower extract of Wedelia trilobata (L.), Hitch. Afr J Biotechnol 2012;11(41):9829-34.

25. Matsubara K, Matsuura Y, Bacic A, Liao M, Hori K, Miyazawa K. Anticoagulant properties of a sulfated galactan preparation from a marine green alga, Codium cylindricum. Int J Biol Macromol 2001;28(5):395-9.

26. Guglielmone HA, Agnese AM, Núñez Montoya SC, Cabrera JL. Anticoagulant effect and action mechanism of sulphated flavonoids from Flaveria bidentis. Thromb Res 2002;105(2):183-8.

27. Kiesewetter H, Jung F, Mrowietz C, Pindur G, Heiden M, Wenzel E, et al. Effects of garlic on blood fluidity and fibrinolytic activity: A randomised, placebo-controlled, double-blind study. Br J Clin Pract Suppl 1990; 69:24-9. 